\title{
Nicotine Addiction and Hearing Loss in Young Subjects From Beirut,
} Lebanon

\author{
Elie El Zir, ${ }^{1}$ Mounir Doumit, ${ }^{2}$ and Ramez Chahine ${ }^{3,}$ \\ ${ }^{1}$ El Arz Hospital, Beirut, Lebanon \\ ${ }^{2}$ Faculty of Dentistry, Lebanese University, Beirut, Lebanon \\ ${ }^{3}$ Faculty of Medical Sciences, Lebanese University, Beirut, Lebanon \\ "Corresponding author: Ramez Chahine, Faculty of Medical Sciences, Lebanese University, Beirut, Lebanon. Tel: +961-3534165, E-mail: rmchahin@ul.edu.lb; \\ charamez@hotmail.com \\ Received 2015 July 14; Revised 2015 August 31; Accepted 2015 September 06.
}

\begin{abstract}
Background: Many studies have established an association between cigarette smoking and Hearing Loss (HL) mostly in subjects working in noisy places. However, few studies are devoted to the relationship between environmental noise and smoking through nicotine addiction.

Objectives: The present study aimed to examine the effect of nicotine dependence on hearing loss and its association with environmental (non-occupational) noise among young subjects in Beirut.

Patients and Methods: The study recruited smokers (100) and non-smokers as a reference group (100) aged 21 to 50 years living in noisy or quiet areas of Beirut [70 to 90 A-weighted decibels (dBA)]. After filling out a questionnaire related to medical history and lifestyle risk factors, including smoking and exposure to noise, each volunteer was subject to a hearing assessment including otoscopy and screening pure-tone air. The incidence of hearing loss was defined as a pure-tone average of thresholds at 2000, 4000 and $8000 \mathrm{~Hz}$ greater than 25-dB hearing level in either ear. Smokers were referred to perform the Fagerstrom test for nicotine dependence. A saliva sample was also collected from all subjects for cotinine determination, a biomarker of exposure to tobacco smoke. Results: The obtained results showed that smoking is associated with hearing loss at $8000 \mathrm{~Hz}$ after age 40 . Current smokers are 1.73 times as likely to have hearing loss as nonsmokers $(\mathrm{P}<0.05)$. Saliva cotinine levels were divided into three categories: group $1(<15$ $\mathrm{ng} / \mathrm{mL}$ ), group $2(16-75 \mathrm{ng} / \mathrm{mL})$ and group $3(76-125 \mathrm{ng} / \mathrm{mL})$. The incidence of hearing loss in each group was, respectively, $13 \%, 16 \%$ and $23 \%(\mathrm{P}<0.05)$.

Conclusions: The significant difference between groups 1 and 3 permits to establish a correlation between degree of nicotine addiction and hearing loss. However, further studies are needed to identify the mechanisms leading to hearing loss.
\end{abstract}

Keywords: Smoking, Hearing Loss, Cotinine, Nicotine Dependence

\section{Background}

Smoking is still the most widespread addiction worldwide. In fact, tobacco addiction may be compared to heroin craving in difficulty to quit. The damage caused by inhaling toxic substances from cigarettes is widely reported. A vast amount of data definitely points to a connection between smoking and diseases of the cardiovascular system, lungs, and malignancy $(1,2)$. On the other hand, scientists have recognized the danger smoking presents to hearing for almost 40 years, though this danger is not studied to the extent of other tobacco-related health risks. Thus, the few reports regarding the relationship between smoking and Hearing Loss (HL) remain equivocal (3, 4). While HL is common among elderly individuals and mostly due to presbyacousis as a normal process of aging, it is less common among young people and is more frequently caused by a combination of genetic and environmental factors. Smoking could be one of the risk factors associated with noise-induced $\operatorname{HL}(5,6)$.

In this context, most surveys were performed in specific places, targeting subjects submitted to occupational (industrial) and non-environmental noises. Environmental noise (also known as community noise or residential noise) is defined as the noises emitted from all sources except that of the workplace $(4,7)$. The main sources of community noise are traffic, construction, public work, and neighborhoods. The open air electricity generators in Lebanon, as well as the frequent use of car horns by drivers, present a significant source of environmental noise pollution across the country, and the heavily populated capital Beirut.

\section{Objectives}

The present study aimed to examine the effect of nicotine dependence on HL and its association with environmental (non-occupational) noise among young subjects in 
Beirut. Fagerstrom test was employed to assess nicotine dependence (8) and cotinine levels in saliva $(9,10)$. To the authors' best knowledge this is the first study to examine the relationship between nicotine addiction, environmental noise and hearing loss.

\section{Patients and Methods}

\subsection{Study Design and Data Collection}

The study population was comprised of 200 volunteers of both genders aged from 21 to 50 years; 100 active smokers, and 100 never smoked. Subjects were divided into four groups:

- G 1: Non-smokers living in different quiet areas of Beirut $(n=50)$.

- G 2: Smokers living in the same quiet areas $(n=50)$.

- G 3: Non-smokers living in different noisy areas of Beirut $(\mathrm{n}=50)$.

- G 4: Smokers living in the same noisy areas $(n=50)$.

All subjects completed the questionnaire including personal data (age, gender), home and work address, smoking status, number of cigarettes per day and duration of smoking in years (using Fagerstrom test for nicotine dependence), as well as all activities or diseases related to hearing.

Subjects who used to smoke, frequent users of mobile phone, hunters, soldiers and ex-soldiers were not included in the study (to rule out acoustic trauma as a cause of hearing loss), as also the subjects with a history of any HL diseases. Subjects from noisy areas were the ones living in noisy areas for at least 20 years, and have their home or workplace on a main street. Subjects from quiet areas were the ones living and working in the same area, and should have never been in noisy environment for more than one hour a day. Smoking categories were defined as follows: non-smokers namely those who never smoked, and smokers divided into three categories namely those who consumed $<10$ cigarettes/day, 10 - 20 cigarettes/day and 20 40 cigarettes/day.

\subsection{Environmental Noise Exposure Assessment}

Outdoor noise was the parameter used to assess the community noise in eight different points of Beirut situated in the corresponding residential areas of the examined population. Measurement of community noise was performed with a sound level meter. Authors used the world health organization (WHO) guideline values to evaluate the measured noise levels. Noisy areas were defined as the places where noise frequencies exceed $65 \mathrm{~A}$ weighted decibels (dBA), and quiet areas were defined as places where noise frequency was below $65 \mathrm{dBA}$.

\subsection{Hearing Test}

Subjects underwent an examination including: otoscopy, screening pure-tone air-conduction and boneconduction audiometry between 500 and $8000 \mathrm{~Hz}$. HL is defined as a pure-tone average hearing level in the ear of greater than 25-dB for 1000 and $2000 \mathrm{~Hz}$, and greater than $40 \mathrm{~dB}$ for 4000 and $8000 \mathrm{~Hz}$. Hearing tests were performed in a sealed, soundproof room with a calibrated clinical audiometer. Cases were defined as those subjects in the top third of the hearing loss distribution (at 2, 4 and $8 \mathrm{kHz}$ ) for their age category, and controls were defined as those subjects in the lowest third of the distribution.

Prevalence ratios (PR) of hearing loss with 95\% confidence interval (CI) were calculated for every factor; a subgroup analysis was then performed taking younger nonsmokers not exposed to environmental noise as a reference group; double and triple exposures were evaluated. Finally, a multivariate analysis was performed, where logistic regression with hearing loss at every frequency was taken as a dependent variable while age, smoking and noise exposure were treated as independent variables.

\subsection{Cotinine Determination}

Nicotine is known to play an important role in smoking addiction in adults. Nicotine has a relatively short half-life (approximately two hours) in the body so that its plasma concentration is primarily a measure of the last few cigarettes smoked. Cotinine, a major metabolite of nicotine, has a longer half-life (approximately 16 hours) and its concentration in plasma and saliva is used as a marker of nicotine intake in adults (10).

Saliva was collected in a plastic vial in the early morning before eating or drinking. Samples were frozen at $20^{\circ} \mathrm{C}$. Saliva cotinine was measured by capillary gas chromatography and nitrogen selective detection, a technique described originally by Feyerabend and Russell (11). Briefly, after centrifuging the saliva sample, a $0.5 \mathrm{~mL}$ aliquot is taken for analysis and N-ethylnorcotinine is added as an internal standard. Then $2 \mathrm{~mL}$ of dichloromethane containing $0.01 \%$ of triethylamine is added, followed by 0.5 $\mathrm{mL}$ of 660 ammonium hydroxide solution. The triethylamine is meant to prevent adsorption of cotinine by glass surfaces. After vortexing and then centrifuging, the aqueous layer is discharged and the dichloromethane is transferred to a $2 \mathrm{~mL}$ GC auto sampler vial and evaporated to dryness. The dry residue is transferred to a $0.3 \mathrm{~mL} \mathrm{GC}$ auto sampler vial using three washes of $100 \mu \mathrm{L}$ of modified dichloromethane, whilst the liquid in the smaller vial is being evaporated. After evaporation of the small vial to dryness, $100 \mu \mathrm{L}$ of modified dichloromethane is added and the vial is sealed and shaken. The current study used an optic 
injection port in the solvent purge mode (not used by Feyerabend and Russell), $50 \mu \mathrm{L}$ is injected from the auto sampler vial in about five seconds. After one minute, the optic split line is closed and the injection port heated to $275^{\circ} \mathrm{C}$. The method had a between-run variation of about $5 \%$ and a detection limit of $0.1 \mathrm{ng} / \mathrm{mL}$ of saliva.

\subsection{Statistics}

Prevalence ratios (PR) of hearing loss with 95\% confidence interval (CI) were calculated for every factor; a subgroup analysis was then performed taking younger nonsmokers not exposed to environmental noise as a reference group; double and triple exposures were evaluated. Finally, a multivariate analysis was performed: a logistic regression with hearing loss at every frequency was taken as a dependent variable and age, smoking and noise exposure as independent variables. The $\mathrm{x}^{2}$ test for general association was used to estimate the relationship between levels of serum cotinine and self-reported smoking status, and between those two variables and incidence of hearing loss. An F test for linear trend was used to assess the relationship between levels of serum cotinine and mean pack-years.

\section{Results}

A subgroup analysis of three factors (smoking, noise, age) is presented in Table 1 . The lowest prevalence was observed in the control group of non-smokers, not exposed to noise, aged 21 - 39 years (6.0\%) and the highest prevalence for smokers exposed to noise aged 40 - 50 years (31.0\%). Analyzed separately or in a combined manner, smoking, noise and age were not positively associated with hearing loss, except for the combination of smoking, noise and age to $8000 \mathrm{~Hz}$, with a prevalence rate of 3.36 (1.25 to 9.6), $\mathrm{P}=0.01$. The results of the current study suggested that smokers over 40 years (smoking more than a pack a day), exposed to community noise, had an increased prevalence of hearing loss.

As shown in Figure 1, salivary cotinine concentration is significantly linked to the number of cigarettes smoked in the last 24 hours. Table 2 presents the saliva cotinine levels related to the number of cigarettes smoked/day and in association with hearing loss at $8000 \mathrm{~Hz}$ becoming significant when the number of cigarette/day is $>20$. Finally, there was a positive correlation between cotinine levels and the score obtained from Fagerstrom test for nicotine dependence (Figure 2).

\section{Discussion}

The current study on environmental noise is original insofar and the introduction of salivary cotinine test is
Table 1. Simultaneous Exposure to Noise, Smoking, and Age on the Hearing Impairment: Subgroup Analysis ${ }^{\mathrm{a}}$

\begin{tabular}{|c|c|c|c|}
\hline $\begin{array}{l}\text { Subgroup } \\
\text { Characteris- } \\
\text { tics Vs. those of } \\
\text { Controls }(\mathbf{n} \\
=50)\end{array}$ & $\begin{array}{c}\text { Deficiency at } \\
2000 \mathrm{~Hz}\end{array}$ & $\begin{array}{c}\text { Deficiency at } \\
4000 \mathrm{~Hz}\end{array}$ & $\begin{array}{c}\text { Deficiency at } \\
8000 \mathrm{~Hz}\end{array}$ \\
\hline \multicolumn{4}{|l|}{ Noise only } \\
\hline $\begin{array}{l}\text { Yes } \\
(100 \%)\end{array}$ & $4(8.0)$ & $5(10.0)$ & $7(14.0)$ \\
\hline $\begin{array}{l}\text { No } \\
(100 \%)\end{array}$ & $3(6.0)$ & $4(8.0)$ & $6(12.0)$ \\
\hline $\begin{array}{l}\mathrm{PR} \\
{[95 \% \mathrm{CI}]}\end{array}$ & $1.33[0.31-5.65]$ & $1.25[0.36-4.39]$ & $1.17[0.42-3.23]$ \\
\hline Pvalue & 1.00 & 1.00 & 0.77 \\
\hline \multicolumn{4}{|l|}{ Smoking only } \\
\hline $\begin{array}{l}\text { Yes } \\
(100 \%)\end{array}$ & $3(6.0)$ & $5(10.0)$ & $9(18.0)$ \\
\hline $\begin{array}{l}\text { No } \\
(100 \%)\end{array}$ & $3(6.0)$ & $4(8.0)$ & $6(12.0)$ \\
\hline $\begin{array}{l}\mathrm{PR} \\
{[95 \% \mathrm{CI}]}\end{array}$ & $1.00[0.21-4.72]$ & 1.25 [0.36 - 4.39]; & 1.50 [0.58 - 3.90]; \\
\hline Pvalue & 1.00 & 1.00 & 0.40 \\
\hline \multicolumn{4}{|l|}{$\begin{array}{l}\text { Noise and } \\
\text { smoking }\end{array}$} \\
\hline $\begin{array}{l}\text { Yes } \\
(100 \%)\end{array}$ & $5(7.1)$ & $11(15.7)$ & $16(22.9)$ \\
\hline $\begin{array}{l}\text { No } \\
(100 \%)\end{array}$ & $3(6.0)$ & $4(8.0)$ & $6(12.0)$ \\
\hline $\begin{array}{l}\text { PR } \\
{[95 \% \mathrm{CI}]}\end{array}$ & $1.21[0.27-.29]$ & 2.14 [0.64 - 7.17] & $2.17[0.78-6.02]$ \\
\hline Pvalue & 1.00 & 0.21 & 0.13 \\
\hline \multicolumn{4}{|l|}{$\begin{array}{l}\text { Smoking, } \\
\text { noise and age } \\
(40-50, y)\end{array}$} \\
\hline $\begin{array}{l}\text { Yes } \\
(100 \%)\end{array}$ & $7(10.0)$ & $14(20.0)$ & $22(31.4 \%)$ \\
\hline $\begin{array}{l}\text { No } \\
(100 \%)\end{array}$ & $3(6.0)$ & $4(8.0)$ & $6(12.0 \%)$ \\
\hline $\begin{array}{l}\mathrm{PR} \\
{[95 \% \mathrm{CI}]}\end{array}$ & $1.74[0.43-7.09]$ & $2.88[0.89-9.33]$ & $3.36[1.25$ - 9.06$]$ \\
\hline Pvalue & 0.43 & 0.07 & 0.01 \\
\hline
\end{tabular}

${ }^{\mathrm{a}}$ Values are expressed as No. (\%).

added as a marker of nicotine dependence in addition to the Fagerstrom test. In fact, this latter gives only a rough estimate of nicotine intake and needs to be supplemented by biochemical measures.

Cotinine is most frequently assayed in plasma samples. Plasma cotinine concentration is highly correlated with tobacco smoke exposure (12). Despite the reliability of plasma samples, blood test results often presents logis- 


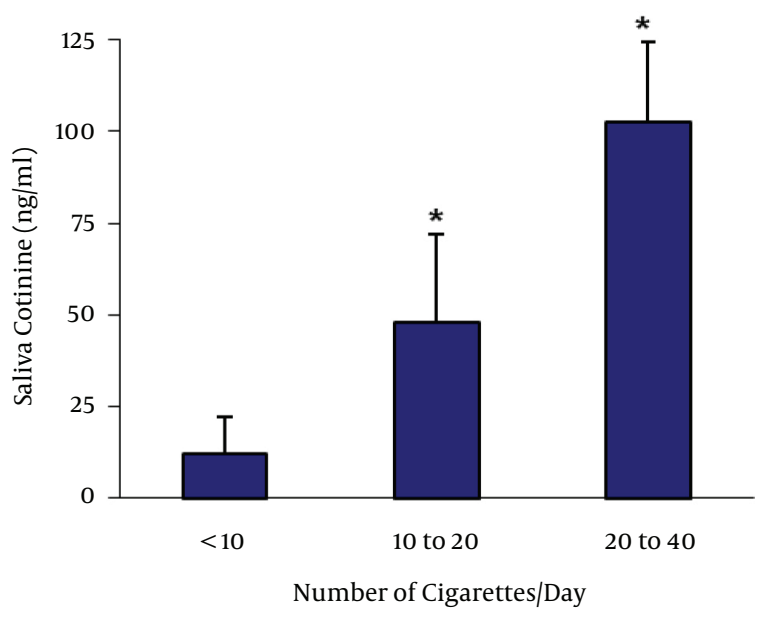

Figure 1. Correlation Between the Number of Cigarettes Consumed and Saliva Cotinine Levels, ${ }^{*} \mathrm{P}<0.05$.

Table 2. Hearing Loss in Association With Saliva Cotinine Levels and the Number of Cigarettes Smoked per Day

\begin{tabular}{lcc}
\hline $\begin{array}{l}\text { Saliva Cotinine } \\
\text { Levels, } \mathbf{n g} / \mathbf{m L}\end{array}$ & Mean Cigarettes/Day & $\begin{array}{c}\text { Rate of Hearing Loss } \\
\text { at } 8000 \mathrm{~Hz}\end{array}$ \\
\hline$<\mathbf{1 5}$ & $<10$ & 13 \\
$\mathbf{1 6}-\mathbf{7 5}$ & $10-20$ & 16 \\
$\mathbf{7 6}-\mathbf{1 2 5}$ & $20-40$ & $23^{\mathrm{a}}$ \\
\hline${ }^{\mathrm{a}} \mathrm{P}<0.05$. & & \\
\hline
\end{tabular}

tical problems in a research setting. Taking blood specimens is invasive and can cause stress and discomfort in some participants. The use of saliva provides an alternative. Salivary testing offers a cost-effective, convenient, non-invasive method to assess cotinine levels and eliminates the discomfort of blood test results. Beyond the logistical advantages, previous research in adult populations suggested that saliva and plasma cotinine levels are highly correlated and have a similar terminal half-life in both matrices (13-15).

In the context of this topic, there are few studies on the combined effects of smoking and exposure to noise among the young subjects. Most of these works, as mentioned above, are related to industrial or non-community noise starting from the first study by Zelman et al. (16) who compared 126 male smokers with 126 male nonsmokers matched by age at a Veterans Administration Hospi$\mathrm{tal}$, and found that hearing thresholds were worse for the smokers than nonsmokers at all frequencies tested (125 $12,000 \mathrm{~Hz}$ ). The association between smoking and noise on hearing loss was reported after that by Barone et al (17). Moreover, Virokannas and Anttonen (18), Noorhassim and

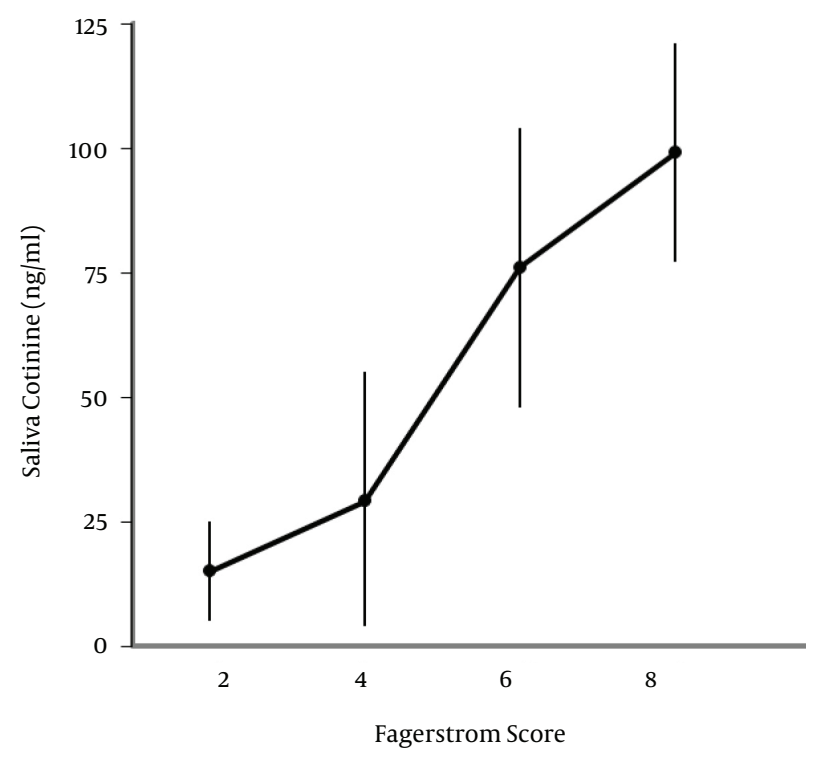

Figure 2. Correlation Between Saliva Cotinine Levels and Fagerstrom Test for Nicotine Dependence

Rampal (19), Palmer et al. (20), Ferrite and Santana (21) and Ohgami et al. (22) observed a positive correlation between the three factors, but without performing bioassays (cotinine). The three combined factors are considered to have an additive rather than synergistic effect; based on most of the previous surveys. The current study was not in agreement with that of Nondahl et al. (23) who did not find an association between cigarette smoking and cotinine in serum. Yet, this same team had reported a positive association (24).

The achieved results through the salivary cotinine determination biologically corroborate the Fagerstrom test of nicotine dependence and can validate the hypothesis that associates the degree of nicotine dependence and environmental noise to hearing loss (Table 2, Figures 1 and 2). It is worth mentioning that ototoxic substances other than nicotine that enter the chemical composition of mainstream cigarette smoke can affect hearing in combination with noise exposure. Cigarette smoking may also affect hearing through its effects on anti-oxidative mechanisms or on the vasculature supplying the auditory system (25), which opens a perspective for future studies in this area.

In conclusion, it is of great importance to give objective advice to civil authority and citizens in order to modify smoking habits, and environmental conditions or residency, which may prevent or delay age-related declines in hearing sensitivity. In addition, smoking per se is dose dependently incriminated with hearing loss at $8000 \mathrm{~Hz}$; 
needless to say that the advantages of stopping smoking will reduce the innumerable harms that this habit causes to otherwise healthy individuals. Bearing in mind that hearing loss is an irreversible phenomenon and is very expensive to treat.

\section{Acknowledgments}

Authors thank research committee of Lebanese University for funding this study.

\section{References}

1. Messner B, Bernhard D. Smoking and cardiovascular disease: mechanisms of endothelial dysfunction and early atherogenesis. Arterioscler Thromb Vasc Biol. 2014;34(3):509-15. doi: 10.1161/ATVBAHA.113.300156. [PubMed: 24554606].

2. Mitchell P, Mok T, Barraclough H, Strizek A, Lew R, van Kooten M. Smoking history as a predictive factor of treatment response in advanced non-small-cell lung cancer: a systematic review. Clin Lung Cancer. 2012;13(4):239-51. doi:10.1016/j.cllc.2011.08.003. [PubMed: 22154074].

3. Starck J, Toppila E, Pyykko I. Smoking as a risk factor in sensory neural hearing loss among workers exposed to occupational noise. Acta Otolaryngol. 1999;119(3):302-5. [PubMed:10380732].

4. Tao L, Davis R, Heyer N, Yang Q, Qiu W, Zhu L, et al. Effect of cigarette smoking on noise-induced hearing loss in workers exposed to occupational noise in China. Noise Health. 2013;15(62):67-72. doi: 10.4103/1463-1741.107159. [PubMed: 23412581].

5. Zhang X, Liu Y, Zhang L, Yang Z, Shao Y, Jiang C, et al. Genetic variations in protocadherin 15 and their interactions with noise exposure associated with noise-induced hearing loss in Chinese population. Environ Res. 2014;135:247-52. doi: 10.1016/j.envres.2014.09.021. [PubMed: 25462672].

6. Wilson LM, Avila Tang E, Chander G, Hutton HE, Odelola OA, Elf JL, et al. Impact of tobacco control interventions on smoking initiation, cessation, and prevalence: a systematic review. J Environ Public Health. 2012;2012:961724. doi: 10.1155/2012/961724. [PubMed: 22719777].

7. Yamasoba T, Lin FR, Someya S, Kashio A, Sakamoto T, Kondo K. Current concepts in age-related hearing loss: epidemiology and mechanistic pathways. Hear Res. 2013;303:30-8. doi:10.1016/j.heares.2013.01.021. [PubMed: 23422312].

8. Etter JF, Duc TV, Perneger TV. Validity of the Fagerstrom test for nicotine dependence and of the Heaviness of Smoking Index among relatively light smokers. Addiction. 1999;94(2):269-81. [PubMed: 10396794].

9. Etzel RA. A review of the use of saliva cotinine as a marker of tobacco smoke exposure. Prev Med. 1990;19(2):190-7. [PubMed: 2193308].

10. Benowitz NL. Cotinine as a biomarker of environmental tobacco smoke exposure. Epidemiol Rev. 1996;18(2):188-204. [PubMed: 9021312].
11. Feyerabend C, Russell MA. A rapid gas-liquid chromatographic method for the determination of cotinine and nicotine in biological fluids. J Pharm Pharmacol. 1990;42(6):450-2. [PubMed: 1979632].

12. Parzynski CS, Jaszyna-Gasior M, Franken FH, Moolchan ET. Measuring nicotine intake among highly-dependent adolescent smokers: comparability of saliva and plasma cotinine concentrations. Pharmacol Biochem Behav. 2008;89(2):145-9. doi: 10.1016/j.pbb.2007.12.003. [PubMed: 18199474].

13. Blackford AL, Yang G, Hernandez-Avila M, Przewozniak K, Zatonski W, Figueiredo $\mathrm{V}$, et al. Cotinine concentration in smokers from different countries: relationship with amount smoked and cigarette type. Cancer Epidemiol Biomarkers Prev. 2006;15(10):1799-804. doi: 10.1158/10559965.EPI-06-0427. [PubMed: 17021350].

14. Figueiredo VC, Szklo M, Szklo AS, Benowitz N, Lozana JA, Casado L, et al. Determinants of salivary cotinine level: a population-based study in Brazil. Rev Saude Publica. 2007;41(6):954-62. [PubMed: 17992352].

15. Fu M, Fernandez E, Martinez-Sanchez JM, Pascual JA, Schiaffino A, Agudo A, et al. Salivary cotinine concentrations in daily smokers in Barcelona, Spain: a cross-sectional study. BMC Public Health. 2009;9:320. doi: 10.1186/1471-2458-9-320. [PubMed:19728886].

16. Zelman DC, Brandon TH, Jorenby DE, Baker TB. Measures of affect and nicotine dependence predict differential response to smoking cessation treatments. J Consult Clin Psychol. 1992;60(6):943-52. [PubMed: 1460156].

17. Barone JA, Peters JM, Garabrant DH, Bernstein L, Krebsbach R. Smoking as a risk factor in noise-induced hearing loss. J Occup Med. 1987;29(9):741-5. [PubMed: 3681506].

18. Virokannas H, Anttonen H. Dose-response relationship between smoking and impairment of hearing acuity in workers exposed to noise. Scand Audiol. 1995;24(4):211-6. [PubMed: 8750748].

19. Noorhassim I, Rampal KG. Multiplicative effect of smoking and age on hearing impairment. Am J Otolaryngol. 1998;19(4):240-3. [PubMed: 9692632].

20. Palmer KT, Griffin MJ, Syddall HE, Coggon D. Cigarette smoking, occupational exposure to noise, and self reported hearing difficulties. Occup Environ Med. 2004;61(4):340-4. [PubMed: 15031392].

21. Ferrite S, Santana V. Joint effects of smoking, noise exposure and age on hearing loss. Occup Med (Lond). 2005;55(1):48-53. doi: 10.1093/occmed/kqio02. [PubMed: 15699090].

22. Ohgami N, Kondo T, Kato M. Effects of light smoking on extra-highfrequency auditory thresholds in young adults. Toxicol Ind Health. 2011;27(2):143-7. doi: 10.1177/0748233710382539. [PubMed: 20858647].

23. Nondahl DM, Cruickshanks KJ, Dalton DS, Schubert CR, Klein BE, Klein R, et al. Serum cotinine level and incident hearing loss: a casecontrol study. Arch Otolaryngol Head Neck Surg. 2004;130(11):1260-4. doi: 10.1001/archotol.130.11.1260. [PubMed: 15545578].

24. Cruickshanks KJ, Klein R, Klein BE, Wiley TL, Nondahl DM, Tweed TS. Cigarette smoking and hearing loss: the epidemiology of hearing loss study. JAMA. 1998;279(21):1715-9. [PubMed: 9624024].

25. Zhan W, Cruickshanks KJ, Klein BE, Klein R, Huang GH, Pankow JS, et al. Modifiable determinants of hearing impairment in adults. Prev Med. 2011;53(4-5):338-42. doi: 10.1016/j.ypmed.2011.08.012. [PubMed: 21871479] 